\title{
Efficacy of two-week therapy with doxycycline-based quadruple regimen versus levofloxacin concomitant regimen for helicobacter pylori infection: a prospective single-center randomized controlled trial
}

\author{
Marouf Alhalabi, Mohammed Waleed Alassi, Kamal Alaa Eddin and Khaled Cheha
}

\begin{abstract}
Background: Antibiotic-resistance reduces the efficacy of conventional triple therapy for Helicobacter Pylori infections worldwide, which necessitates using various treatment protocols. We used two protocols, doxycyclinebased quadruple regimen and concomitant levofloxacin regimen. The aim was to assess the effectiveness of doxycycline-based quadruple regimen for treating Helicobacter Pylori infections compared with levofloxacin concomitant regimen as empirical first-line therapy based on intention-to-treat (ITT) and per-protocol analyses (PPA) in Syrian population.

Settings and design: An open-label, randomised, parallel, superiority clinical trial.

Methods: We randomly assigned 78 naïve patients who tested positive for Helicobacter Pylori gastric infection, with a 1:1 ratio to (D-group) which received (bismuth subsalicylate $524 \mathrm{mg}$ four times daily, doxycycline $100 \mathrm{mg}$, tinidazole $500 \mathrm{mg}$, and esomeprazole $20 \mathrm{mg}$, each twice per day for 2 weeks), or (L-group) which received (levofloxacin $500 \mathrm{mg}$ daily, tinidazole $500 \mathrm{mg}$, amoxicillin $1000 \mathrm{mg}$, and esomeprazole $20 \mathrm{mg}$ each twice per day for two weeks). We confirmed Helicobacter Pylori eradication by stool antigen test 8 weeks after completing the treatment.
\end{abstract}

Results: Thirty-nine patients were allocated in each group. In the D-group, 38 patients completed the follow-up, 30 patients were cured. While in the L-group, 39 completed the follow-up, 32patients were cured. According to ITT, the eradication rates were $76.92 \%$, and $82.05 \%$, for the D-group and L-group respectively. Odds ratio with $95 \%$ confidence interval was 1.371 [0.454-4.146]. According to PPA, the eradication rates were $78.9 \%$, and $82.05 \%$ for the D-group and L-group respectively. The odds ratio with 95\% confidence interval was 1.219 [0.394-3.774]. We didn't report serious adverse effects.

\footnotetext{
*Correspondence: e.marouf@hotmail.com

Gastroenterologist at Damascus Hospital, Almujtahed street, Damascus, Syria
}

C C The Author(s). 2021 Open Access This article is licensed under a Creative Commons Attribution 4.0 International License, which permits use, sharing, adaptation, distribution and reproduction in any medium or format, as long as you give appropriate credit to the original author(s) and the source, provide a link to the Creative Commons licence, and indicate if changes were made. The images or other third party material in this article are included in the article's Creative Commons licence, unless indicated otherwise in a credit line to the material. If material is not included in the article's Creative Commons licence and your intended use is not permitted by statutory regulation or exceeds the permitted use, you will need to obtain permission directly from the copyright holder. To view a copy of this licence, visit http://creativecommons.org/licenses/by/4.0/. The Creative Commons Public Domain Dedication waiver (http://creativecommons.org/publicdomain/zero/1.0/) applies to the data made available in this article, unless otherwise stated in a credit line to the data. 
Conclusions: Levofloxacin concomitant therapy wasn't superior to doxycycline based quadruple therapy. Further researches are required to identify the optimal first-line treatment for Helicobacter-Pylori Infection in the Syrian population.

Trial registration: We registered this study as a standard randomized clinical trial (Clinicaltrial.gov, identifierNCT04348786, date:29-January-2020).

Keywords: Helicobacter pylori, Doxycycline, Tinidazole, Bismuth, Quadruple regimen, Levofloxacin, Syria

\section{Background}

Eastern Mediterranean region countries have a high prevalence rate of Helicobacter Pylori (H.Pylori) infection [1]. Chronic infection of H. pylori contributes to multiple diseases such as peptic ulcer disease and subsequent bleeding [2-4], dyspepsia, gastric adenocarcinoma [5], mucosa-associated lymphoid tissue (MALT) lymphoma [6], idiopathic thrombocytopenic purpura [7], and unexplained iron deficiency anaemia [8]. World health organization has listed the H.Pylori infection as a class 1 carcinogen [9]. Eradication of H.Pylori cures previous diseases and can decrease the risk of gastric cancer [10]. Eradication rate of $H$. pylori infection is declining globally due to increased antibiotic resistance particularly clarithromycin and levofloxacin [11]. In the eastern Mediterranean area, the resistance to clarithromycin, metronidazole, levofloxacin, amoxicillin, and tetracycline were $29 \%, 61 \%, 23 \%, 14 \%, 10 \%$ respectively [12]. Several researchers reviewed many therapeutic regimens including sequential, concomitant, and hybrid to find the best treatment protocol [13]. The results of conventional triple therapy in Syria were disappointing [14]. Currently tetracycline is unavailable in Syria, so we used doxycycline in the bismuth quadruple regimen $[15,16]$. Although tinidazole isn't superior to metronidazole in treating Helicobacter Pylori infections [17], we used tinidazole instead of metronidazole in both regimens, as $H$. pylori had high metronidazole resistance rate [18]. Metronidazole is a commonly overused drug in Syria, mainly prescribed for gynaecological and gastrointestinal diseases [19] Besides, tinidazole (b.i.d) is more tolerable by patients. There is a lack of data about the efficacy of doxycycline-based quadruple regimen and levofloxacincontaining quadruple concomitant regimen in Syrian patients, we conducted this trial to evaluate the efficacy and report the eradication rate of these regimens according to Intention-to-treat analysis (ITT) and per-protocol analysis (PPA).

\section{Methods}

This was a prospective single-center open-label parallel randomized superiority controlled clinical trial. It was conducted at gastroenterology department, Damascus hospital, Syria. We recruited appropriate candidates from patients who visited our clinic for evaluation of dyspeptic symptoms by upper gastrointestinal endoscopy between February 2020 and August 2020. Exclusion criteria were (1) younger than 18 years and older than 80 years; (2) prior eradication treatment for $\mathrm{H}$ pylori; (3) documented reactions to any of the studied medications; (4) recent use of antibiotics, bismuth, or proton pump inhibitors (PPIs) in the preceding month; (5) pregnant or lactating women; (6) previous gastric surgery; (7) alcohol or opioid abuse; and (8) severe concurrent medical illnesses, such as liver failure, renal failure, or terminal malignancy.

\section{H. pylori detection}

All patients have undergone upper gastrointestinal endoscopy. Endoscopists have taken five gastric biopsies; two from the antrum, two from the body, and one from the incisura according to the Sydney system [20]. Pathologists confirmed $H$. pylori infection by microscopic examination after using haematoxylin, eosin, and Giemsa stains [21]. We sent all biopsies to the central pathological laboratory of the same referral hospital.

\section{Intervention}

Eligible patients were randomized in a 1:1 ratio to receive 2 weeks of treatment of either doxycycline-based regimen (D-group) or concomitant levofloxacin regimen (L-group). The D-group obtained bismuth subsalicylate $524 \mathrm{mg}$ q.i.d, doxycycline $100 \mathrm{mg}$, tinidazole $500 \mathrm{mg}$, esomeprazole $20 \mathrm{mg}$ each b.i.d for 14 days. While the Lgroup obtained levofloxacin $500 \mathrm{mg}$ q.d, tinidazole 500 $\mathrm{mg}$, amoxicillin $1000 \mathrm{mg}$, and esomeprazole $20 \mathrm{mg}$ each b.i.d for 14 days. The indication of treatment relied on the American College of gastroenterology guideline and Maastricht V/Florence consensus report [13, 15] including peptic ulcer, chronic gastritis, primary gastric MALT lymphoma, intestinal metaplasia, dyspepsia, and unexplained iron deficiency anaemia.

We used a Microsoft Excel function called (RANDBETWEEN) to generate a sequence of two randomized numbers, number one referred to the $\mathrm{D}$-group, and number two referred to the L-group. We printed each code on separate paper, inserted it into sealed opaque envelopes in unchanged order, and hold it in a secure 
locker belonging to an independent medical staff member. After obtaining informed consent, the independent medical staff member took the top envelope to assign the patient to the treatment regimen. We provided all patients with written instructions considering medication dosage. We evaluated compliance by counting the number of unused medications and considered that the patient was complaint if he/she had taken at least $90 \%$ of the assigned treatment protocol.

At the end of the treatment course, patients revisited the clinic to investigate side effects and evaluate compliance. We reported side effects such as nausea, vomiting, diarrhoea, melena, dysgeusia, and anorexia. After 8 weeks, all patients visited the central laboratory of our hospital and undergone stool antigen tests by using the enzyme immunoassay method (EIA) [22]. Medical laboratory workers were blinded to the treatment arm. Qualified physician collected the data in a questionnaire including (1) participants' demographics; (2) smoking history; (3) medication history; (4) adverse events, and (5) results of stool antigen test. Numerical data were shown as mean, and qualitative data were expressed as a ratio.

Authors reported the results according to the CONSORT.

\section{Outcomes}

This study aims to assess the effectiveness of doxycycline-based quadruple regimen for treating Helicobacter Pylori infections compared with levofloxacin concomitant regimen.

\section{Sample size and statistical analysis}

We reviewed English medical literature for Helicobacter Pylori doxycycline-based therapy and found a systematic review authored by Niv [16]. There aren't new studies yet. We reviewed the studies within it and found that nine clinical trials excluded bismuth, two clinical trials replaced proton pump inhibitors with ranitidine, and two clinical trials used different doxycycline therapeutic protocol (LOND: levofloxacin, omeprazole, nitanoxanide, and doxycycline) [23]. The remaining two studies: Borody TJ et al. reported the eradication rate of doxycycline based therapy as first line treatment and it was 0.65 [24],while Wang et al. reported the eradication rate of doxycycline based therapy as second-line treatment based on ITT, It was 0.6744 [25]. Those results were close and we chose the highest eradication rate. Federico et al. found that the eradication rate based on ITT was $0.922 \%$ in concomitant levofloxacin-containing therapy [26]. To find if concomitant levofloxacin-containing regimen was more effective than doxycycline-based regimen we conducted a clinical trial with superior study design. We used a power $(1-\beta)$ of $80 \%$, two tails test and significance level $(\alpha)$ equal to $5 \%$, with a $1: 1$ allocation ratio. Each treatment arm required 37 patients [27]. We added two patients to each group to compensate for the predicted dropout $[28,29]$.

Statistical tests: Chi-square test ( $\mathrm{x}^{2}$-test) for categorical variables, and t-test for continuous data. We reported the odds ratio with a $95 \%$ confidence interval. A $P$-value less than 0.05 was considered statistically significant. We performed statistical analyses using SPSS (IBM Corp. Released in 2017. IBM SPSS Statistics for Windows, Version 25.0. Armonk, NY: IBM Corp).

\section{Results}

We collected 226 patients diagnosed with $H$. pylori infection confirmed by biopsy. Seventy-eight treatmentnaive patients were enrolled in this study (39 patients for each group), only one patient in D-group didn't complete the follow-up. [Fig. 1 and Table 1] summarizes the flow chart and baseline characteristics of the patients. The gender, mean age and pharmacological side effects were similar among treatment groups, except for melena, which occurred more frequently in the D-group.

H. pylori infection was eradicated in 30 patients from the D-group, and 32 patients from the L-group. Table 2 summarised the eradication rates according to ITT and PPA analysis. We didn't report serious adverse effects.

\section{Discussion}

Researchers globally observe a decline in the rate of $\mathrm{H}$ pylori eradication following standard triple therapies, thus requiring a search for new therapeutic approaches [45-48]. This randomized clinical trial included 78 patients from an area of high prevalence $(>15 \%)$ of clarithromycin and levofloxacin resistant helicobacter pylori strains $[1,12,14$, $30,31]$. Both concomitant and bismuth-containing quadruple therapies are recommended as alternative first-line treatment according to the previously mentioned guidelines, particularly in regions with a high prevalence of clarithromycin resistance $[13,15]$.

The eradication rate for levofloxacin concomitant protocol was $82.05 \%$ according to ITT analysis, while doxycycline-based therapy had a PPA eradication rate of $78.94 \%$, and $76.92 \%$ according to ITT analysis. The overall eradication rate of levofloxacin concomitant was about 3\% higher than doxycycline-based therapy but the difference didn't reach statistical significance. The result of levofloxacin containing therapy can be regarded as Grade D standard, while the result of bismuthcontaining therapy can be regarded as Grade $\mathrm{F}$ as proposed recently [32]. The former results are better than our preceding study outcomes regarding the treatment of $H$. pylori [14]. Our results are agreeing with a metaanalysis by Essa et al. and similar research by Federico et al. Both studies showed that concomitant therapy is 


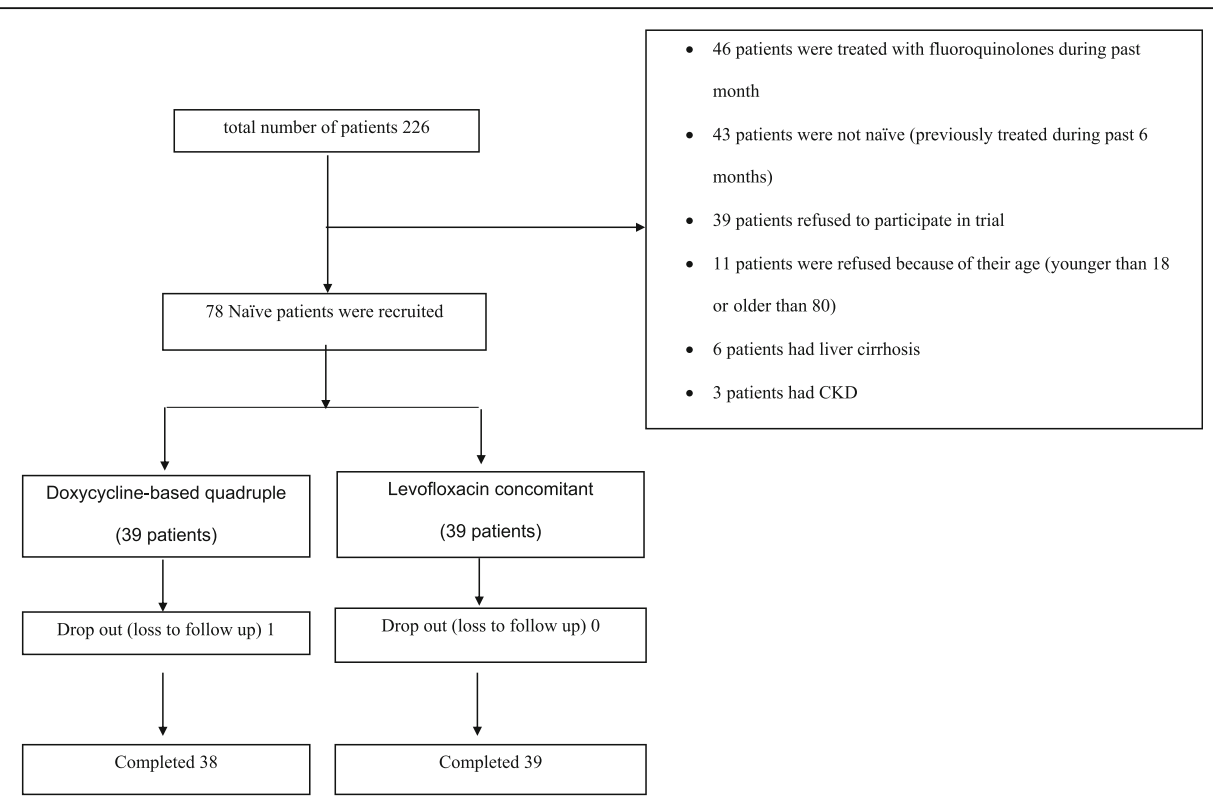

Fig. 1 Flow of the study

effective in the eradication of H.Pylori [26, 33]. Similarly, meta-analysis by Niv et al. found that the Doxycyclinebased quadruple regimen had good efficacy in the treatment of Helicobacter Pylori infection [16] .Even though this research treated patients for a longer period [34], our results didn't show the effectiveness mentioned in previous studies, this may be due to the existence of Helicobacter Pylori resistant strains [35]. Antibiotics are overused,especially macrolides and fluoroquinolones, for treating respiratory, urinary and gynaecological infections [36-38]. Chokshi et al. reported that the main contributors of emerging antibiotic resistance in developing countries are clinical mismanagement, antibiotics availability, poor quality of available antibiotics, and insufficient surveillance of resistance development [39]. We checked compliance by counting remaining pills which raised suspicions about outpatient incompliance to antibiotic regimens [40-42].

Our study has a few limitations (1) The only method to investigate medication history was to interrogate patients. Electronic medical were lacking, The patient was considered "naïve" if he/she wasn't previously treated for

Table 1 Baseline characteristics of patients

\begin{tabular}{llll}
\hline & doxycycline-based quadruple regimen & levofloxacin concomitant regimen & $P$-value \\
\hline Gender & $21(55.3 \%)$ & & $20(51.3 \%)$ \\
Male & $17(44.7 \%)$ & $19(48.7 \%)$ & 0.821 \\
Female & $41.82 \pm 11.914$ & $45.62 \pm 17.994$ & 0.223 \\
Age (mean years tSD) & $16(42.1 \%)$ & $16(41 \%)$ & 1.00 \\
Smoking & $2(5.3 \%)$ & $0(2.5 \%)$ & 0.240 \\
Alcoholic & & & 0.160 \\
Adverse events & $5(13.2 \%)$ & $5(28.2 \%)$ & 0.160 \\
Anorexia & $10(26.3 \%)$ & $4(10.3 \%)$ & 0.347 \\
Nausea & $7(18.4 \%)$ & $11(28.2 \%)$ & 0.421 \\
Vomiting & $7(18.4 \%)$ & $0(0 \%)$ & 0.0001 \\
Dysgeusia & $11(28.9 \%)$ & $0(0 \%)$ & 0.494 \\
Melena & $1(2.6 \%)$ & $3(7.7 \%)$ & 0.310 \\
Discoloured Tongue & $6(15.8 \%)$ & & \\
Diarrhea & & & \\
\hline
\end{tabular}


Table 2 Helicobacter pylori eradication rate

\begin{tabular}{lllll}
\hline & levofloxacin concomitant regimen & doxycycline-based quadruple regimen & Odds Ratio $(\mathbf{9 5 \%} \mathrm{Cl})$ & $\boldsymbol{P}$-Value \\
\hline ITT & $82.1 \%$ & $76.9 \%$ & $1.371(0.454,4.146)$ & 0.78 \\
PPA & $82.1 \%$ & $78.9 \%$ & $1.219(0.394,3.774)$ & 0.78 \\
\hline
\end{tabular}

$\mathrm{Cl}$ confidence interval, ITT intention to treat analysis, PPA per-protocol analysis

H. pylori infection;(2) We depended on patients to evaluate the compliance ;and (3) We didn't perform a susceptibility test of $H$. pylori to antibiotics, because it's unavailable in Syria.

This study showed that both regimens had an acceptable rate of eradication, and the difference didn't reach statistical significance. These results were highly promising in treating $H$. pylori infection in Syria.

\section{Conclusion}

The success rate of the standard triple therapy with clarithromycin or levofloxacin has declined substantially due to increasing antimicrobial resistance. (ACG) Clinical guideline and Maastricht Consensus recommended alternative regimens, including bismuth-containing quadruple therapy or non-bismuth concomitant therapy, as first-line therapies, particularly in areas with a high prevalence of clarithromycin resistance like Syria. Levofloxacin concomitant therapy wasn't superior to doxycycline based quadruple therapy, we didn't record any serious adverse event in both regimens. We encourage further researches to determine the optimal first-line empirical therapy for Helicobacter-Pylori Infection in the Syrian population.

\section{Abbreviations}

PPA: Per-protocol analysis; ITT: Intention to treat analysis; q.i.d.: Four times a day; b.i.d.: Twice a day; q.d: Once a day; ACG: American College of Gastroenterology; H. pylori: Helicobacter Pylori; PPI: Proton pump inhibitors

\section{Acknowledgements}

Not Applicable.

\section{Priprint}

https://www.researchsquare.com/article/rs-250381/v1

DOl:https://doi.org/10.21203/rs.3.rs-250,381/v1

\begin{abstract}
Authors' contributions
Marouf Alhalabi established the conceptualization, wrote the main manuscript text, prepared (Tables 1 and 2) and performed statistics. Mohammed Waleed Alassi wrote the main manuscript text,collected data, Kamal Alaa Eddin prepared Fig. 1, (Tables 1 and 2). Khaled Cheha executed supervision. All authors had reviewed and approved the final manuscript.
\end{abstract}

\section{Funding}

Not Applicable, None. No funding to declare.

\section{Availability of data and materials}

The dataset supporting the conclusions of this article is available for free in the [data.mendeley.com] repository, [https://data.mendeley.com/drafts/ fzv77yzshx], and it will be available after 15 September 2021 to 15 September 2023.

\section{Declarations}

Ethics approval and consent to participate

All methods were carried out in accordance with relevant guidelines and regulations.

All experimental protocols were approved by the Ethical Committee of the general assembly of Damascus Hospital (Approval No:5-30-12-19).

Written informed consent was obtained from all patients or their legally authorized representatives. If the patient is under 18, the informed consent was obtained from a parent and/or legal guardian. It was clearly stated that only clinical information will be shared in research, without mentioning any personal details at any part of the article.

Consent for publication

Not applicable.

\section{Competing interests}

The authors declare that there is no conflict of interest

Received: 24 April 2021 Accepted: 18 June 2021

Published online: 04 July 2021

\section{References}

1. Hooi JKY, Lai WY, Ng WK, Suen MMY, Underwood FE, Tanyingoh D, et al. Global prevalence of helicobacter pylori infection: systematic review and meta-analysis. Gastroenterology. 2017;153(2):420-9. https://doi.org/10.1053/j. gastro.2017.04.022

2. Peterson WL. Helicobacter pylori and peptic ulcer disease. N Engl J Med. 1991;324(15):1043-8. https://doi.org/10.1056/NEJM199104113241507.

3. Caselli M, Alvisi V. Helicobacter pylori and peptic-ulcer disease. Lancet. 2002; 359(9321):1943-4. https://doi.org/10.1016/S0140-6736(02)08746-9.

4. Henriksson AE, Edman AC, Held M, Wadström T. Helicobacter pylori and acute bleeding peptic ulcer. Eur J Gastroenterol Hepatol. 1995;7(8):769-71.

5. Ishaq S, Nunn L. Helicobacter pylori and gastric cancer: a state of the art review. Gastroenterol Hepatol Bed Bench. 2015;8(Suppl 1):S6-14.

6. Wotherspoon AC. Gastric MALT Iymphoma and helicobacter pylori. Yale J Biol Med. 1996;69(1):61-8.

7. Kim BJ, Kim HS, Jang HJ, Kim JH. Helicobacter pylori eradication in idiopathic thrombocytopenic Purpura: a meta-analysis of randomized trials. Gastroenterol Res Pract. 2018;2018:1-8. https://doi.org/10.1155/2018/ 6090878.

8. Monzón H, Forné M, Esteve M, Rosinach M, Loras C, Espinós JC, et al. Helicobacter pylori infection as a cause of iron deficiency anaemia of unknown origin. World J Gastroenterol. 2013;19(26):4166-71. https://doi. org/10.3748/wjg.v19.i26.4166

9. Schistosomes, liver flukes and Helicobacter pylori. IARC Working Group on the Evaluation of Carcinogenic Risks to Humans. Lyon, 7-14 June 1994. IARC Monogr Eval Carcinog Risks Hum. 1994;61:1-241.

10. Helicobacter pylori Eradication to Prevent Gastric Cancer in a High-Risk Region of China: A Randomized Controlled Trial | Gastroenterology | JAMA | JAMA Network. https://jamanetwork.com/journals/jama/fullarticle/197985. Accessed 4 Jul 2020.

11. Ghotaslou R, Leylabadlo HE, AsI YM. Prevalence of antibiotic resistance in helicobacter pylori: a recent literature review. World J Methodol. 2015;5(3): 164-74. https://doi.org/10.5662/wjm.v5.i3.164.

12. Savoldi A, Carrara E, Graham DY, Conti M, Tacconelli E. Prevalence of Antibiotic Resistance in Helicobacter pylori: A Systematic Review and Metaanalysis in World Health Organization Regions. Gastroenterology. 2018;155: 1372-82 e17.

13. Malfertheiner P, Megraud F, O'Morain CA, Gisbert JP, Kuipers EJ, Axon AT, et al. Management of Helicobacter pylori infection-the Maastricht V/ Florence consensus report. Gut. 2017:66(1):6-30. https://doi.org/10.1136/ gutjnl-2016-312288. 
14. Cheha KM, Dib SOA, Alhalabi MM. Pilot study: comparing efficacy of 14-day triple therapy clarithromycin versus levofloxacin on eradication of helicobacter pylori infection in Syrian population single-center experience. Avicenna J Med. 2018;8(1):14-7. https://doi.org/10.4103/ajm.AJM_70_17.

15. Chey WD, Leontiadis GI, Howden CW, Moss SF. ACG clinical guideline: treatment of helicobacter pylori infection. Am J Gastroenterol. 2017;112. https://journals.lww.com/ajg/Fulltext/2017/02000/ACG_Clinical_Guideline_ Treatment_of_Helicobacter.12.aspx(2):212-39. https://doi.org/10.1038/ajg.201 6.563.

16. Niv Y. Doxycycline in eradication therapy of helicobacter pylori--a systematic review and meta-analysis. Digestion. 2016;93(2):167-73. https:// doi.org/10.1159/000443683.

17. Berrutti M, Pellicano R, Astegiano M, Smedile A, Saracco G, Morgando A, et al. Helicobacter pylori eradication: metronidazole or tinidazole? Data from Turin, Italy. Minerva Gastroenterol Dietol. 2008;54(4):355-8.

18. Moshkowitz M, Konikoff FM, Peled Y, Brill S, Hallak A, Tiomny E, et al. One week triple therapy with omeprazole, clarithromycin and tinidazole for helicobacter pylori: differing efficacy in previously treated and untreated patients. Aliment Pharmacol Ther. 1996;10(6):1015-9. https://doi.org/10.104 6/j.1365-2036.1996.96268000.x.

19. Hart CA, Kariuki S. Antimicrobial resistance in developing countries. BMJ. 1998;317(7159):647-50. https://doi.org/10.1136/bmj.317.7159.647.

20. Satoh K, Kimura K, Taniguchi Y, Kihira K, Takimoto T, Saifuku K, et al. Biopsy sites suitable for the diagnosis of helicobacter pylori infection and the assessment of the extent of atrophic gastritis. Am J Gastroenterol. 1998; 93(4):569-73. https://doi.org/10.1111/j.1572-0241.1998.166_b.x.

21. Lee JY, Kim N. Diagnosis of helicobacter pylori by invasive test: histology. Ann Transl Med. 2015;3. https://doi.org/10.3978/j.issn.2305-5839.2014.11.03.

22. Veijola L, Myllyluoma E, Korpela R, Rautelin H. Stool antigen tests in the diagnosis of helicobacter pylori infection before and after eradication therapy. World J Gastroenterol. 2005;11(46):7340-4. https://doi.org/10.3748/ wjg.v11.i46.7340

23. Basu PP, Rayapudi K, Pacana T, Shah NJ, Krishnaswamy N, Flynn M. A randomized study comparing levofloxacin, omeprazole, Nitazoxanide, and doxycycline versus triple therapy for the eradication of helicobacter pylori. Am J Gastroenterol. 2011;106(11):1970-5. https://doi.org/10.1038/ajg.2011.3 06.

24. Borody TJ, George LL, Brandl S, Andrews P, Lenne J, Moore-Jones D, et al. Helicobacter pylori eradication with doxycycline-metronidazole-bismuth subcitrate triple therapy. Scand J Gastroenterol. 1992;27(4):281-4. https://doi. org/10.3109/00365529209000075.

25. Wang Z, Wu S. Doxycycline-based quadruple regimen versus routine quadruple regimen for rescue eradication of helicobacter pylori: an openlabel control study in Chinese patients. Singap Med J. 2012;53(4):273-6.

26. Federico A, Nardone G, Gravina AG, lovene MR, Miranda A, Compare D, et al. Efficacy of 5-day levofloxacin-containing concomitant therapy in eradication of Helicobacter pylori infection. Gastroenterology. 2012;143:5561 e1; quize e13-14.

27. Zhong B. How to calculate sample size in randomized controlled trial? J Thorac Dis. 2009;1(1):51-4.

28. Gupta K, Attri J, Singh A, Kaur H, Kaur G. Basic concepts for sample size calculation: critical step for any clinical trials! Saudi J Anaesth. 2016;10(3): 328-31. https://doi.org/10.4103/1658-354X.174918.

29. Sakpal TV. Sample size estimation in clinical trial. Perspect Clin Res. 2010;1:67.

30. Eshraghian A. Epidemiology of helicobacter pylori infection among the healthy population in Iran and countries of the eastern Mediterranean region: a systematic review of prevalence and risk factors. World J Gastroenterol. 2014;20(46):17618-25. https://doi.org/10.3748/wjg.v20.i46.1 7618.

31. Kuo Y-T, Liou J-M, El-Omar EM, Wu J-Y, Leow AHR, Goh KL, et al. Primary antibiotic resistance in helicobacter pylori in the Asia-Pacific region: a systematic review and meta-analysis. Lancet Gastroenterol Hepatol. 2017; 2(10):707-15. https://doi.org/10.1016/S2468-1253(17)30219-4.

32. Graham DY, Lu H, Yamaoka Y. A report card to grade helicobacter pylori therapy. Helicobacter. 2007;12(4):275-8. https://doi.org/10.1111/j.1523-5378.2 007.00518.x

33. Essa AS, Kramer JR, Graham DY, Treiber G. Meta-analysis: four-drug, threeantibiotic, non-bismuth-containing "concomitant therapy" versus triple therapy for Helicobacter pylori eradication. Centre for Reviews and Dissemination (UK); 2009. https://www.ncbi.nlm.nih.gov/books/NBK77292/. Accessed 4 Sep 2020.
34. Yuan Y, Ford AC, Khan KJ, Gisbert JP, Forman D, Leontiadis GI, Tse F, Calvet X, Fallone C, Fischbach L, Oderda G, Bazzoli F, Moayyedi P. Optimum duration of regimens for Helicobacter pylori eradication. Cochrane Database Syst Rev. 2013;(12):CD008337. https://doi.org/10.1002/14651858.CD008337. pub2.

35. Haddadi M-H, Negahdari B, Asadolahi R, Bazargani A. Helicobacter pylori antibiotic resistance and correlation with cagA motifs and homB gene. Postgrad Med. 2020;:1-4l.

36. Levy SB, Star L, Kupferberg ED. The misuse of antibiotice. Medical Ethics (Burlington, Mass). 2004;11:5-8.

37. Schroeck JL, Ruh CA, Sellick JA, Ott MC, Mattappallil A, Mergenhagen KA. Factors associated with antibiotic misuse in outpatient treatment for upper respiratory tract infections. Antimicrob Agents Chemother. 2015;59(7):384852. https://doi.org/10.1128/AAC.00652-15.

38. Giono-Cerezo S, Santos-Preciado Jl, Morfin-Otero MDR, Torres-Lopez FJ, Alcantar-Curiel MD. Antimicrobial resistance. Its importance and efforts to control it. Gac Med Mex. 2020;156(2):171-8. https://doi.org/10.24875/GMM. M20000358

39. Chokshi A, Sifri Z, Cennimo D, Horng H. Global contributors to antibiotic resistance. J Global Infect Dis. 2019;11(1):36-42. https://doi.org/10.4103/jgid. jgid_110_18.

40. Kardas P. Patient compliance with antibiotic treatment for respiratory tract infections. J Antimicrob Chemother. 2002;49(6):897-903. https://doi.org/10.1 093/jac/dkf046.

41. Grob PR. Antibiotic prescribing practices and patient compliance in the community. Scand J Infect Dis Suppl. 1992;83:7-14.

42. Eells SJ, Nguyen M, Jung J, Macias-Gil R, May L, Miller LG. Relationship between adherence to Oral antibiotics and Postdischarge clinical outcomes among patients hospitalized with Staphylococcus aureus skin infections. Antimicrob Agents Chemother. 2016;60(5):2941-8. https://doi.org/10.112 8/AAC.02626-15.

\section{Publisher's Note}

Springer Nature remains neutral with regard to jurisdictional claims in published maps and institutional affiliations.
Ready to submit your research? Choose BMC and benefit from:

- fast, convenient online submission

- thorough peer review by experienced researchers in your field

- rapid publication on acceptance

- support for research data, including large and complex data types

- gold Open Access which fosters wider collaboration and increased citations

- maximum visibility for your research: over $100 \mathrm{M}$ website views per year

At $\mathrm{BMC}$, research is always in progress.

Learn more biomedcentral.com/submissions 